\title{
Fazendo Eleitores e Eleições: Mobilização Política e Democracia no Brasil Pós-Estado Novo*
}

\author{
Fernando Limongi
}

Universidade de São Paulo (USP), São Paulo, SP, Brasil. E-mail: fplimongi@gmail.com

\begin{abstract}
F $\mathrm{m}$ 1953, discursando na Câmara dos Deputados, Guilhermino de ¿ Oliveira, do Partido Democrático Social de Minas Gerais (PDS-MG) afirma: "somos eleitos por eleitores que fazemos com o maior sacrifício". Para o deputado, só poderiam contestar sua afirmação aqueles que "nunca fizeram eleições nem eleitores e nada conhecem do que se passa no interior do país, como se faz qualificações ou como se processam as eleições" (Diário do Congresso Nacional, 19/12/1953:5795, ênfases minhas).
\end{abstract}

Fazer eleitores era alistá-los, isto é, torná-los aptos a tomar parte do processo eleitoral. Políticos faziam eleitores porque sabiam como as criaturas a que davam vida viriam a votar. Para tanto, deviam incorrer em doses extras de "sacrifícios", custeando o transporte e fornecendo as cédulas com as escolhas devidamente impressas a serem depositadas nas urnas. Assim, políticos podiam estar certos de que eram eleitos pelos eleitores que haviam feito e que, consequentemente, fazer eleitores era apenas o passo inicial para "fazer a eleição". Participar de elei-

\footnotetext{
* Agradeço a Andréa Freitas, Andrea Junqueira e Saulo Said pelo auxílio no levantamento do material usado neste artigo. Os comentários de José Antonio Cheibub, Daniel Gingerich e Daniel Hidalgo e todos os participantes do seminário Rediscovering Brazil, Núcleo de Estudos Comparados e Internacionais (NECI), 9 e 10 de dezembro de 2013. Um agradecimento especial a Andréa Freitas, Jaqueline Zulini, Argelina Figueiredo, Glauco Peres e Maria Hermínia Tavares, cujos comentários me forçaram a rever a versão original do texto. A responsabilidade pelas imprecisões e confusões é inteiramente minha.
}

DADOS - Revista de Ciências Sociais, Rio de Janeiro, vol. 58, no2 2, 2015, pp. 371 a 400. 
ções, portanto, está longe de ser uma decisão voluntária. Participavam os eleitores feitos, mobilizados por terceiros.

A se crer neste depoimento, referendado, como veremos ao longo deste artigo, pela crônica política e por outros tantos parlamentares, as práticas eleitorais da Primeira República (1889-1930) e da Terceira República (1945-1964) não seriam muito diversas. As eleições de 1945, contudo, marcaram uma ruptura fundamental na história política do país. A queda do Estado Novo marca o início de nossa primeira experiência democrática, rompendo com uma experiência que se estendera por mais de cem anos em que eleições eram controladas pelo governo. Governantes passaram a sofrer derrotas eleitorais. Dito de forma inversa: oposições passaram a ter chances reais de chegar ao poder.

Práticas eleitorais foram preservadas, mas as eleições ganharam novo caráter, passando a ser competitivas. À primeira vista, estas duas proposições não poderiam ser conciliadas. Em geral, assume-se que "a liberdade do voto" é a condição necessária para a emergência de eleições competitivas. Em artigo anterior (Limongi, 2012), mostrei que o controle sobre o eleitor não é suficiente para eliminar a competição eleitoral. Neste artigo, sugiro que a independência dos eleitores não é condição necessária para a emergência de eleições competitivas.

Para usar os termos de Cox (2005), eleições competitivas não exigem que partidos se dediquem à persuasão dos eleitores ${ }^{1}$. Competição pode ocorrer mesmo quando políticos fazem eleitores e sabem de antemão que serão eleitos por aqueles que fizeram. O eleitor vota de acordo com a vontade daquele que lhe providenciou o título, transportou e lhe forneceu as cédulas previamente preenchidas. Pode haver certeza quanto aos votos individuais e incerteza quanto aos resultados.

Há competição quando diferentes partidos lutam para fazer mais eleitores que os demais e são capazes de fazer com que seus eleitores votem. Nesta situação, partidos competem por eleitores, e não por votos. Para que haja competição é necessário que mais de um partido possa conduzir "magotes de eleitores" às urnas "como quem toca tropa de burros" (Leal, 1993:43). Para retornar à terminologia de Cox (2005), mobilização é a atividade essencial para a ocorrência de eleições competitivas. Políticos são sempre eleitos pelos eleitores que fazem. Muda apenas a forma como eleitores são feitos. 
O artigo está organizado da seguinte forma: além desta introdução, a segunda seção reconstitui a queda do Estado Novo, frisando a importância da perda de controle do governo sobre o processo eleitoral que desencadeara e a consequência deste fato para a formação e composição dos partidos políticos. A terceira relaciona a legislação à mobilização eleitoral que, como procuro mostrar, não se resume ao alistamento ex-officio. Chamo a atenção para a definição ambígua das fronteiras da cidadania política e para as possibilidades abertas para o alistamento coletivo feito por terceiros. A quarta seção procura caracterizar as práticas eleitorais vigentes. Indico que, para os políticos, as atividades eleitorais fundamentais eram o alistamento (fazer eleitores), o transporte e a distribuição de cédulas (fazer as eleições). A última seção extrai as consequências do discutido para o entendimento da emergência de eleições competitivas.

\section{A TRANSIÇÃO À DEMOCRACIA}

Em sua análise seminal sobre a transição de 1945, Maria do Carmo Campello de Souza (1990) realça as continuidades entre o Estado Novo e o regime democrático nascente. A ênfase no controle e na influência de Vargas sobre a eleição e seu resultado faz com que a autora minimize as consequências da queda do Estado Novo. Afinal, se Vargas tinha tamanho controle sobre a transição, por que foi deposto? Ao realçar a continuidade, a análise perde de vista a ruptura ocorrida, minimizando as incertezas do processo eleitoral. O fato é que se continuidade houve, esta só foi assegurada após conhecido o resultado das eleições.

Sabemos hoje, graças ao trabalho de Ângela Castro Gomes (2005), que o governo perdeu o controle sobre o processo que deslanchara. Se bem-sucedido, aí sim as eleições seriam mera fachada. Como demonstra esta autora, o projeto inicial de Vargas era o de obter um novo mandato presidencial por meio de uma eleição não competitiva. O governo tinha de fato um plano, chamado Plano $B$, como nomeado nos documentos secretos de Vargas depositados no Centro de Pesquisa e Documentação de História Contemporânea do Brasil (CPDOC).

O controle sobre o processo de alistamento, a ser feito com base nos sindicatos oficiais, incluindo sindicatos rurais, era a peça central da estratégia do governo. A essência desta estratégia era, em realidade, uma atualização da máxima enunciada por Belisário Soares de Souza quase cem anos antes: "feita uma boa qualificação, está quase decidida a elei- 
ção" (1979:27). Desde a aprovação da Lei Saraiva, em 1881, a qualificação dos eleitores passou a ser fortemente controlada. Mais do que as restrições legais de renda e de educação, os controles formais (documentação exigida) passaram a funcionar como um filtro a restringir a participação política² .

Compor adequadamente o eleitorado pede a neutralização dos esforços dos adversários. Por isto mesmo, no caso do Plano B, previa-se que o alistamento e a eleição deveriam ser feitos rapidamente, impedindo assim a reorganização política das velhas oligarquias, cuja força eleitoral, de acordo com este documento, se basearia "nos serviços de alistamento de um eleitorado mais ou menos pessoal. Era esta a hierarquia: o eleitor ligado ao cabo eleitoral que o alistava; o cabo submetido aos chefes municipais - vereadores, prefeitos, fazendeiros - e estes obedientes a um dos chefes estaduais conforme a zona de influência"”3.

O Plano B, elaborado pelo ministro da Justiça e do Trabalho, Marcondes Filho, não contou com apoio unânime de lideranças ligadas a Vargas e ao Estado Novo. Como observa Ângela Castro Gomes (2005:276), referindo-se especificamente às movimentações e intenções de Oswaldo Aranha, candidato a suceder Vargas, não eram pequenas as divisões no interior das elites governamentais. Como se sabe (Dulles, 1967:269), as pretensões presidenciais de Aranha foram obstadas de forma clara pelo empastelamento da Sociedade Amigos da América, ação em que o general Eurico Gaspar Dutra desempenhou papel de destaque.

Obviamente, o brigadeiro Eduardo Gomes não poderia receber o mesmo tratamento, posto que, como observa Ângela Castro Gomes (2005:276), sua candidatura "tinha certamente origens militares e provavelmente contava com a indulgência dos americanos". A cartada certeira do grupo mais próximo aos Estados Unidos coloca Vargas e seu círculo íntimo na defensiva. Agamenon Magalhães assume o Ministério da Justiça (desmembrado do Ministério do Trabalho) e passa a ser o principal responsável por traçar a estratégia política do governo. O lançamento da candidatura do general Eurico Gaspar Dutra é parte desta estratégia, visando dividir as Forças Armadas, impedindo assim que estas convergissem para uma candidatura única. Vale ressaltar: o governo não escolhe seu próprio candidato. Lançar Dutra foi a alternativa para ganhar tempo ${ }^{4}$.

Agamenon Magalhães, portanto, improvisa um Plano C. A guinada, contudo, não significou o abandono completo da alternativa coorde- 
nada por Marcondes Filho. Conforme afirma Ângela Castro Gomes (2005:282):

No início de 1945 se estabeleceu a hipótese de que as forças ligadas a Vargas se mobilizassem em duas, e não apenas em uma organização partidária [...]. O PTB, neste sentido, nasceu ao mesmo tempo que o PSD, já que ambos resultaram da frustração do projeto de partido único de massas que vinha sendo acalentado pelo Estado Novo.

Ainda que tenha sido assim, as diferenças entre as duas alternativas e a relação de Vargas com cada uma delas é evidente. Vargas não abraça ou encampa com entusiasmo a candidatura Dutra. Este, de sua parte, nunca deixa de desconfiar das intenções continuístas do ditador, expressas em sua conivência com o Queremismo.

Dentro da estratégia desenhada por Agamenon Magalhães, o Partido Social Democrata (PSD) ganha autonomia e vida própria, escapando ao controle direto de Vargas. Os interventores preparam-se para vencer a eleição e assumir o controle sobre a política em seus estados (Hippolito, 1985:119)5. Em boa medida, recorrem às velhas práticas políticas que o Plano B queria sepultar. De outra parte, as relações entre PSD e o Partido Trabalhista Brasileiro (PTB) estão longe de correr por trilhos paralelos e complementares como pretende o folclore político que atribui à astúcia e maquiavelismo do velho ditador a criação dos dois partidos. Nada mais significativo neste sentido do que a admoestação de Agamenon Magalhães a Segadas Vianna: “Quem chegar em Pernambuco falando em PTB eu baixo o pau" (Gomes, 2005:283).

O PTB (ibidem:289; Delgado, 1989:62) não apoia a candidatura Dutra de forma imediata. Quando o faz, a decisão não é unânime ou automática. Opta-se, ao final, pelo mal menor, e somente após obter concessões significativas.

Se é verdade que Vargas inventa o trabalhismo (Gomes, 2005), não parece ser menos verdadeiro que ele não dispensa o mesmo zelo e recursos para criar e preparar o PTB para a disputa eleitoral que se aproximava. O ditador nunca abandonou sua opção pela continuidade, pelo adiamento das eleições, cuja expressão política foi o movimento queremista.

Os resultados eleitorais colhidos pelo PTB em 1945 apontam para o improviso e a alta dependência do partido para com o prestígio pessoal do ditador deposto. Enquanto UDN (União Democrática Nacional) e 
PSD lançam candidatos em todos os estados, o PTB marca presença apenas em 14 das 22 unidades da Federação. O dado é mais significativo quando se leva em consideração que o Partido Comunista Brasileiro (PCB), por seu turno, apresenta candidatos em todos os estados. Além disto, a votação pessoal de Vargas representa algo como $50 \%$ da votação do PTB para a Câmara dos Deputados ${ }^{6}$. Dos oito estados em que o partido obtém representação, somente em um deles (Amazonas), Getúlio não encabeça a lista. Em todos estes sete estados o partido não ultrapassaria o quociente eleitoral sem a votação pessoal de Vargas. Em boa parte destes, a votação de Vargas é dez vezes maior que a do segundo mais votado da lista apresentada pelo PTB.

A recomposição das forças políticas ao final do Estado Novo segue o padrão observado usualmente em quedas de regimes autoritários (Przeworski, 1991:54). Questões de encaminhamento, em especial as relativas à forma de assegurar a sobrevivência política dos de dentro são tão ou mais importantes que as desavenças substantivas e ideológicas. Quebrada a unidade em torno da preservação e continuidade do regime, as forças políticas se recompõem rapidamente.

Fundamental para o entendimento da queda do Estado Novo e suas consequências é ter claro que as divisões no interior do próprio regime impulsionaram o processo. Estas divisões foram profundas. As Forças Armadas se dividem. Não é irrelevante que as duas principais candidaturas tenham tido origem militar.

A cisão no interior das elites civis não é menor. Vale observar que boa parte dos que tramam a candidatura do brigadeiro Eduardo Gomes e participaram da fundação da UDN haviam mantido boas relações com Vargas e, mesmo, com o Estado Novo ${ }^{7}$. Alternativas à estratégia desenhada por Marcondes Filho foram gestadas no interior do regime, incluindo a candidatura Oswaldo Aranha, cuja proximidade com os Estados Unidos é conhecida. Assim, é possível traçar uma linha que liga as pretensões presidenciais de Oswaldo Aranha à criação da $\mathrm{UDN}^{8}$. As divisões não foram menos relevantes entre os que permaneceram sob a órbita de Vargas. PSD e PTB, para não falar no Queremismo, têm bases de apoio e foram regidos por lógicas políticas diversas. O importante é ressaltar que tanto o PSD quanto a candidatura Dutra ganharam autonomia em relação ao projeto pessoal de Vargas, que nunca abandonou o projeto continuísta. 
Ao longo de 1945, o governo não recupera sua unidade. Ainda que mantenha a iniciativa e tenha controle sobre a elaboração da legislação eleitoral, manipulando-a a seu favor, atuou sob fortes restrições, impostas tanto pela força da oposição quanto por sua incapacidade de superar suas divisões internas. A Lei Agamenon foi uma pálida imagem do Plano B.

O desfecho do processo, a deposição de Vargas, indica os limites da influência e controle do ditador e seu círculo íntimo sobre a transição. As Forças Armadas se unem para depor Getúlio e garantir a eleição, adotando a fórmula defendida pela UDN, isto é, a transferência do poder para o Judiciário, mais precisamente, ao presidente do Supremo Tribunal Federal, José Linhares.

Victor Nunes Leal (1993:237), após revisar a história político-eleitoral do Brasil desde a independência, enfatiza as características "excepcionais em nossa história política" da eleição de 1945, uma vez que estas teriam sido marcadas pela "isenção de ânimos dos governantes na direção da eleição" ${ }^{\prime \prime}$.

A neutralidade do governo José Linhares é o resultado do processo descrito anteriormente. Tendo concordado em depor Vargas, eliminada a alternativa continuísta, Dutra e Gomes tinham que optar entre a guerra civil e a disputa eleitoral. Escolheram a segunda alternativa ${ }^{10}$.

\section{A LEGISLAÇÃO ELEITORAL E A MOBILIZAÇÃO DE ELEITORES}

O alistamento ex-officio pode ser visto como o que a Lei Agamenon preservou do Plano B (Gomes, 2005:280). Na interpretação de Maria do Carmo Campello de Souza (1990:121), o recurso a este expediente teria conferido à eleição de 1945, "senão um caráter de fraude oficializada, pelo menos um viés considerável".

Neste ponto em realidade, a autora faz eco às denúncias de setores da UDN que creditaram sua derrota ao controle exercido pelo governo sobre o processo de alistamento dos eleitores, em especial dos trabalhadores urbanos ${ }^{11}$.

De fato, o pleito de dezembro de 1945 foi precedido por forte mobilização eleitoral, mas este processo não se resumiu ao alistamento promovido pelo Estado, tampouco se concentrou nos centros urbanos. Em menos de seis meses, se tomarmos a promulgação da Lei Agamenon $(28 / 5 / 1945)$ como o ponto de partida, pouco mais de 7,4 milhões de 
eleitores foram alistados, o que representava 16\% da população em idade de votar. O contraste com a participação nas eleições anteriores é significativo. Nas eleições presidenciais de 1930, o eleitorado inscrito não alcançara 2,5 milhões ou $5,7 \%$ da população adulta ${ }^{12}$.

Parte deste crescimento pode ser creditada às mudanças legais, como a diminuição da idade legal para votar e a extensão do direito de voto às mulheres. Contudo, menos que a relação com a população total ou mesmo com a adulta, o que deve ser frisado é o número absoluto de eleitores alistados em tão pouco tempo. O esforço para mobilizar eleitores foi enorme.

Conforme recorda Amaral Peixoto, a estratégia seguida pelos políticos "era fazer o alistamento eleitoral em massa... Se fossem levar eleitor por eleitor, não teriam a base que conseguiram. Uma eleição que se fazia em Niterói com 10 mil eleitores passou a ser feita com 100 mil" (apud Nicolau, 2012:95).

Contudo, não se deve assumir que o alistamento ex-officio era a única alternativa à disposição dos partidos e dos políticos interessados em incorporar eleitores ao processo eleitoral. Tampouco se deve pensar que este esforço mobilizador tenha se concentrado ou se dado majoritariamente nas áreas urbanas.

A Lei Agamenon previa duas modalidades de alistamento, o ex-officio e o por requerimento. A contraposição entre estas duas alternativas leva a crer que a segunda se daria de forma voluntária e individual. Além disso, as denúncias da UDN associam a ação do Estado ao alistamento fraudulento de analfabetos e de estrangeiros. No entanto, tais suposições não contam toda a história. Em primeiro lugar, deve-se notar que a Lei Agamenon era suficientemente ambígua para permitir que os requerimentos para alistamento fossem apresentados por terceiros em favor de grupos de eleitores ${ }^{13}$.

A Tabela 1 mostra que o peso do alistamento ex-officio sobre a composição do eleitorado é bem menor do que a estridência das reclamações da UDN faz supor: não mais que um quarto do eleitorado fora alistado desta forma. Ainda que não tenha sido desprezível, não se pode dizer que esta forma de alistamento preponderou. Sobretudo, está longe de ser fundamental no interior, onde se concentrava a maior parte do eleitorado. 
Tabela 1

Alistamento em 1945 por Modalidade e Status do Município

\begin{tabular}{|c|c|c|c|c|c|}
\hline \multirow{2}{*}{$\begin{array}{l}\text { Unidade da } \\
\text { Federação }\end{array}$} & \multicolumn{2}{|c|}{ Capital (\%) } & \multicolumn{2}{|c|}{ Interior (\%) } & \multirow{2}{*}{ Total } \\
\hline & Ex-officio & Requerimento & Ex-officio & Requerimento & \\
\hline $\mathrm{AM}$ & 22,5 & 31,6 & 4,5 & 41,4 & 31.948 \\
\hline PA & 13,8 & 27,0 & 3,7 & 55,6 & 159.395 \\
\hline MA & 7,9 & 7,8 & 3,9 & 80,4 & 109.101 \\
\hline PI & - & - & - & - & - \\
\hline $\mathrm{CE}$ & 4,8 & 9,2 & 3,4 & 82,5 & 369.550 \\
\hline $\mathrm{RN}$ & 2,9 & 10,3 & 5,9 & 81,0 & 131.560 \\
\hline PB & 4,4 & 6,5 & 5,3 & 83,9 & 175.634 \\
\hline PE & 13,9 & 13,2 & 7,2 & 65,7 & 321.736 \\
\hline $\mathrm{AL}$ & 11,0 & 13,4 & 11,6 & 64,0 & 82.068 \\
\hline SE & 9,2 & 10,2 & 6,1 & 74,5 & 97.089 \\
\hline BA & 7,4 & 11,7 & 9,9 & 71,0 & 440.621 \\
\hline ES & 6,8 & 9,8 & 8,3 & 75,1 & 122.281 \\
\hline RJ & 6,3 & 6,2 & 25,4 & 62,1 & 383.100 \\
\hline SP & 18,3 & 20,4 & 14,7 & 46,5 & 1.688 .598 \\
\hline PR & 10,7 & 11,5 & 10,9 & 66,9 & 229.672 \\
\hline SC & 2,2 & 4,5 & 17,2 & 76,1 & 248.086 \\
\hline RS & 7,4 & 8,0 & 13,6 & 71,0 & 753.232 \\
\hline MG & 2,9 & 4,5 & 11,7 & 80,9 & 1.231 .251 \\
\hline GO & 2,3 & 7,0 & 5,1 & 85,6 & 103.079 \\
\hline MT & 4,0 & 16,4 & 11,7 & 67,9 & 59.121 \\
\hline DF & 54,1 & 45,9 & 0,0 & 0,0 & 549.353 \\
\hline Total & 12,7 & 14,3 & 11,1 & 62,0 & 7.286 .475 \\
\hline
\end{tabular}

Fonte: Tribunal Superior Eleitoral, Dados Estatísticos.

Nota: Não há dados para o Piauí.

Por sua vez, a Tabela 2 traz estatísticas publicadas pelo Superior Tribunal Eleitoral (TSE) que indicam que o contingente de eleitores alistados em 1945 tangenciou o eleitorado potencial em uma série de estados. Considerando os dados agregados para o Brasil, vê-se que 8 em 10 eleitores potenciais foram inscritos. Ainda que haja considerável variação por estados, parece evidente que o esforço de mobilização foi enorme. A maioria dos que reuniam condições para votar foi alistada.

Os dados revelam que este esforço não foi uniforme, sendo maior em alguns estados do que em outros. Contudo, o fato mais relevante des- 
Tabela 2

Eleitorado Alistado e Potencial por Estado

(1945)

\begin{tabular}{l|c|c|c}
\hline Estado & $\begin{array}{c}\text { Eleitorado } \\
\text { (a) }\end{array}$ & $\begin{array}{c}\text { Potencial } \\
(\mathbf{b})\end{array}$ & $\begin{array}{c}\text { (a)/(b) } \\
(\mathbf{\%})\end{array}$ \\
\hline AM & 31.948 & 101.071 & 31,6 \\
PA & 159.395 & 244.197 & 65,3 \\
MA & 109.101 & 163.704 & 66,6 \\
PI & 132.455 & 96.755 & 136,9 \\
CE & 369.550 & 335.206 & 110,2 \\
RN & 131.560 & 130.388 & 100,9 \\
PB & 175.634 & 187.409 & 93,7 \\
PE & 321.736 & 434.515 & 74,0 \\
AL & 82.068 & 115.983 & 70,8 \\
SE & 97.089 & 87.737 & 110,7 \\
BA & 440.621 & 620.140 & 71,1 \\
ES & 122.281 & 174.570 & 70,0 \\
RJ & 383.100 & 471.358 & 81,3 \\
SP & 1.688 .598 & 1.899 .241 & 88,9 \\
PR & 229.672 & 294.068 & 78,1 \\
SC & 248.086 & 306.756 & 80,9 \\
RS & 753.232 & 1.062 .770 & 70,9 \\
MG & 1.231 .251 & 1.392 .885 & 88,4 \\
GO & 103.079 & 119.603 & 86,2 \\
MT & 59.121 & 102.854 & 57,5 \\
DF & 549.353 & 825.315 & 66,6 \\
\hline Brasil & 7.418 .930 & 9.166 .525 & 80,9 \\
\hline
\end{tabular}

Fonte: Tribunal Superior Eleitoral, Dados Estatísticos.

tes dados é que em alguns estados, especificamente no Piauí, Ceará, Rio Grande do Norte e Sergipe, o número de alistados excedeu o legalmente possível. Nestes, de acordo com as estimativas do próprio TSE, eleitores sem a qualificação necessária, a alfabetização, teriam sido alistados de forma ilegal. Não é preciso conhecer profundamente a estrutura social brasileira para notar que estes não são estados nos quais predomina a urbanização e/ou há concentração de estrangeiros. Ou seja, se houve fraude no alistamento, esta não se concentrou nas áreas urbanas e/ou foi levada a cabo recorrendo exclusivamente ao alistamento ex-officio. Basta voltar à Tabela 1 para verificar que, exceto para o 
Piauí, onde não há dados, nestes estados o alistamento por requerimento predomina sobre o ex-officio e o eleitorado do interior sobre o da capital.

Contudo, deve ser notado que ao apresentar os dados contidos na Tabela 2, o TSE não explicita os critérios utilizados para definir o eleitorado potencial. Em realidade, atendo-se à letra da Lei, o Tribunal não teria como fazê-lo. A Lei Agamenon, como de resto toda a legislação eleitoral republicana até então, negava o direito de voto aos analfabetos sem estabelecer os critérios a serem seguidos para aplicar a proibição estipulada ${ }^{14}$. Significativamente, não há menção a documentos ou qualquer outro tipo de comprovação que deveriam ser fornecidos para comprovar a qualificação requerida.

Implicitamente, sabia ler e escrever quem assim afirmasse. No máximo, a prova seria dada pela capacidade de assinar os requerimentos e o próprio título. Contudo, como boa parte desta tarefa poderia ser feita por terceiros, a exigência, na prática, não era um obstáculo difícil de ser transposto ${ }^{15}$.

Assim, taxas de alistamento superiores a 100\% do eleitorado potencial não necessariamente indicam alistamento fraudulento. Indicam, isto sim, que as fronteiras da cidadania política eram fluidas e indefinidas $^{16}$. Foram assim durante todo o período republicano. Dito de outra forma: as fronteiras da cidadania não podem ser inferidas diretamente das definições constitucionais ou da legislação.

O contraste entre a baixa participação política na Primeira República e a forte mobilização que caracteriza o início da Terceira República não pode ser explicado, quer pelas fronteiras formais da cidadania, quer por possíveis mudanças na estrutura social.

Não há dados que discriminem os eleitores alistados por local de residência. Contudo, a estrutura social do país permite supor que a maior parte do eleitorado continuava a residir no campo e a se dedicar a atividades primárias. Os dados apresentados e analisados por Kinzo (1980:90) permitem concluir que, deste ponto de vista, o Brasil não mudara muito ao longo dos 15 anos do governo Vargas. Conforme nota esta autora, em 1920, para cada trabalhador no setor secundário havia 6,56 empregadas no setor primário. Esta relação caiu para 5,82 em 1940 e para 4,22 em 1950. Quanto ao local de residência, apoiando-se no trabalho de Vilmar Faria, Kinzo (1980:91) mostra que a porcentagem da 
população urbana brasileira seria de 16,6\%, em 1920,15,1\%, em 1940, e $19,9 \%$, em $1950^{17}$.

Deve-se notar ainda que, como mostra Kang (2010:57), as mudanças no perfil educacional da população brasileira ao longo dos 15 anos de governo de Vargas não foram significativas. Pelos dados compilados por este autor, a porcentagem da população acima de 5 anos de idade e alfabetizada era de 24,5\%, em 1920. Em 1940 esta proporção subira para $38,2 \%$ e chega a $42,7 \%$, em 1950 .

As transformações estruturais da sociedade brasileira não são suficientes para dar conta do contraste entre o baixo e o alto grau de mobilização eleitoral verificados na Primeira e na Terceira República. Como veremos adiante, a despeito do voto secreto, as práticas eleitorais tampouco sofreram alterações profundas. Modernização e/ou a Justiça Eleitoral não explicam a emergência da competição eleitoral. A diferença crucial está na legislação, na diminuição do controle sobre o processo de alistamento de eleitores ${ }^{18}$. Paradoxalmente, o alistamento ex-officio, previsto no Código Eleitoral de 1932, faz parte de uma série de medidas visando simplificar os requisitos formais exigidos para a inscrição de eleitores ${ }^{19}$. O objetivo destas reformas era retirar do governo e/ ou seus representantes locais os meios para impedir que as oposições alistassem eleitores.

Voltando à mobilização ocorrida em 1945, parece apenas razoável supor que os dois principais partidos envolvidos na disputa, PSD e UDN, tenham recorrido aos meios condenados pelo Plano B. Cada um buscou usar dos meios à sua disposição para filiar o maior número de adeptos e, desta forma, vencer as eleições. As incertezas quanto aos resultados do pleito alimentaram a mobilização de eleitores, alistados em massa nas cidades e no campo. A condição para o deslanche desta competição é a cisão no interior da elite política, e a manifestação prática desta cisão é que ambas as partes, governo e oposição, tenham como fazer seus eleitores.

O eleitorado do PSD, com certeza, não se resumiu a eleitores alistados pelos sindicatos e órgãos públicos ${ }^{20}$, tampouco se poderia supor que a UDN contou com o apoio apenas de eleitores que tenham se inscrito de forma voluntária. Em boa medida, restaurou-se o que o Plano B pretendia erradicar; as práticas políticas das velhas máquinas oligárquicas foram reativadas pelas elites políticas acomodadas tanto no PSD quanto na UDN. Contudo, estas práticas se desenrolam sob um marco legal 
em que grupos políticos locais perdem a capacidade de controlar a formação do corpo eleitoral.

A aprovação do Código Eleitoral de 1950 não significou alteração radical do quadro legal instaurado pela Lei Agamenon. O Código, é certo, atende as principais demandas UDN, revogando as medidas que, na visão do partido, haviam beneficiado o PSD e, de forma mais geral, o varguismo. O alistamento ex-officio é abolido ${ }^{21}$, candidaturas múltiplas vedadas e o método D'Hondt passa a regular a distribuição de sobras nas eleições proporcionais.

Mais importante, contudo, é o que o novo marco legal preservou a indefinição das fronteiras da cidadania política e os baixos custos formais para alistar eleitores. O Código não estipulou quais provas ou documentos deveriam ser apresentados para comprovar que o alistando sabia ler e escrever ${ }^{22}$. Mais do que isto, a possibilidade do alistamento feito por terceiros e de forma coletiva foi preservada. O art. 37 do Código previa explicitamente que os títulos poderiam ser entregues ao procurador do eleitor, isto é, ao chefe político que havia "feito o eleitor". O detalhe não é insignificante, uma vez que isto indicava que os responsáveis por fazer eleitores poderiam reter os títulos em suas mãos. Os custos formais e as práticas envolvidas foram preservados.

Em última análise, as indefinições e ambiguidades do Código tornavam letra-morta a restrição do voto aos analfabetos. Ao longo da tramitação do Código esta questão não é levantada quer pelo PSD, quer pela UDN. Vale frisar que à época da aprovação do Código os dois partidos se encontravam coligados (Leal, 1993; Amorim Neto, 1995; Figueiredo, 2007).

Os dois partidos, portanto, quando aprovam o novo Código, concordam que continuariam a "fazer eleitores" aproveitando-se das ambiguidades e brechas deixadas pela legislação. Em virtude dos desdobramentos posteriores, o ponto talvez peça ênfase. Ao participar da aprovação do Código de 1950, a UDN não empunha a bandeira da moralização das práticas políticas. Isto seria feito no futuro, em outro momento, quando o partido altera a sua estratégia política. Em 1950, a UDN e o PSD concordam em manter e explorar as ambiguidades das fronteiras da cidadania política que traçam.

Deste modo, o processo de mobilização eleitoral iniciado em 1945 se estendeu à eleição de 1950, quando o número de eleitores registrados 
alcança a marca de 11,4 milhões, registrando, assim, um crescimento de 53,5\% em menos de cinco anos. Boa parte deste crescimento se concentra no ano que antecede as novas eleições gerais. Em 1949, o eleitorado registrado era composto por 8,7 milhões de eleitores. Em um único ano, portanto, precisamente no que antecede a eleição geral, ocorreu um crescimento de $30 \%$ no total de eleitores inscritos ${ }^{23}$.

Estatísticas publicadas pelo TSE permitem caracterizar o processo em curso. A Figura 1 mostra claramente que a maioria dos novos eleitores foi alistada meses antes da eleição. O alistamento, portanto, não seguiu padrão esperado tivesse ele ocorrido de forma voluntária e individual, com os eleitores se alistando quando alcançavam a idade legal para votar. Antes das eleições, políticos redobram seus esforços para "fazer eleitores". O TSE publica gráficos como este para estados específicos e para eleições estaduais e municipais. A norma é a mesma: picos de alistamento nos meses que antecedem eleições específicas. O incremento do eleitorado, contudo, é bem mais pronunciado no ano que antecede a eleição geral.

O intenso processo de mobilização eleitoral se estende até a eleição de 1955. O clima político deste período, contudo, é outro. O acordo tácito entre o PSD e a UDN em torno das fronteiras da cidadania política é rompido ao longo do governo Vargas. A UDN passa a defender reformas moralizadoras da legislação eleitoral, isto é, que aumentem as exigências e custos para incorporar eleitores e fazê-los votar. Contudo, como o PSD derrota as primeiras reformas propostas pela UDN, as eleições legislativas de 1954 são regidas pelo Código de 1950. Para as eleições presidenciais de 1955, a UDN obtém uma importante concessão do PSD, que acaba aceitando a adoção da cédula oficial naquela oportunidade ${ }^{24}$. No entanto, as propostas específicas visando o recadastramento do eleitorado foram derrotadas ${ }^{25}$. Por isto mesmo o eleitorado continuou a crescer de forma acelerada, ultrapassando a marca dos 15 milhões nas eleições presidenciais de 1955. Em dez anos de democracia, o eleitorado dobra, enquanto a população cresce por volta de $25 \%$.

Em resumo, os anos iniciais da Terceira República são marcados por amplo processo de mobilização eleitoral. Esta não se resume à entrada das camadas urbanas na política sob a tutela do varguismo e dos sindicatos atrelados ao Estado. Não há dúvidas que este processo ocorreu, mas não foi este o traço preponderante do período. PSD e UDN, naquele momento, tinham suas bases eleitorais no campo; a relativa permis- 
Fazendo Eleitores e Eleições

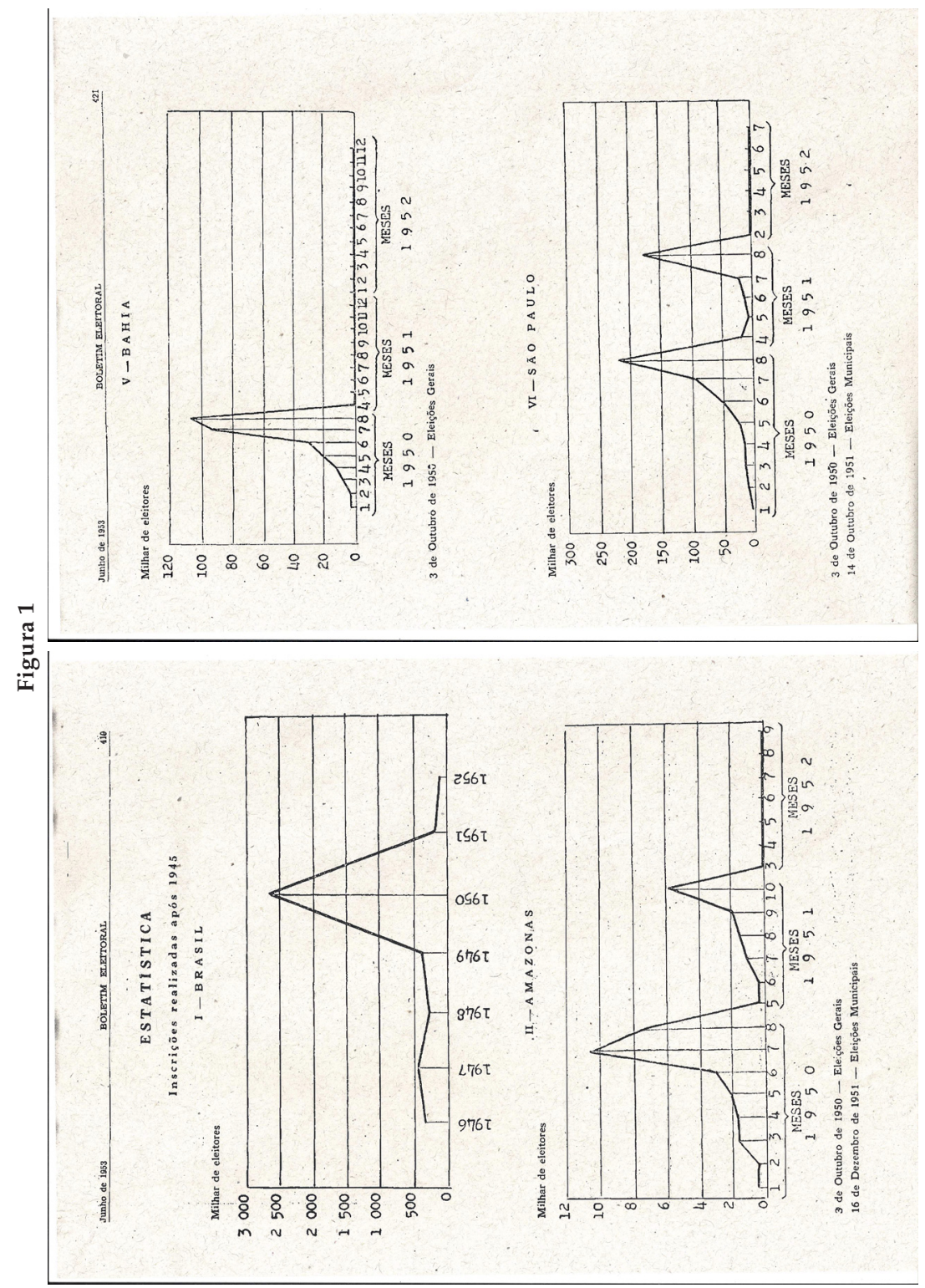

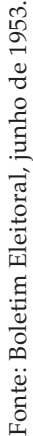


sividade da legislação eleitoral, expressa nos baixos custos formais exigidos para alistar eleitores, permitiu que agentes políticos se lançassem à tarefa de fazer eleitores.

\section{ATIVIDADES ELEITORAIS E SEUS CUSTOS}

Há uma extensa literatura tratando das práticas eleitorais no Império e na Primeira República. Nestes trabalhos, em geral, ressalta-se a ausência das condições institucionais e estruturais para a participação política regular. $\mathrm{O}$ tema perde importância na literatura que discute o regime inaugurado em 1945. Implicitamente, assume-se que os problemas experimentados ao longo de mais de cem anos com eleições estariam resolvidos ou, no mínimo, em vias de sê-lo. Do ponto de vista institucional, a criação da Justiça Eleitoral e a adoção do voto secreto limitariam a influência que a violência e a fraude teriam tido até então. No que se refere à estrutura social, a urbanização e a industrialização do país diminuiriam o peso do eleitorado rural e dos controles tradicionais que cerceavam a liberdade do voto.

Entretanto, do ponto de vista das práticas eleitorais, a ruptura entre a Primeira e a Terceira Repúblicas não é grande, se é que ela existe. A adoção do voto secreto não retira dos políticos a capacidade de controlar o comportamento dos eleitores. A emergência da competição eleitoral se dá sem alterações profundas na forma como eleitores eram levados a votar.

Os debates ocorridos ao longo da tramitação do Projeto de Lei no 870, de 1952, apresentado pelo deputado Tarso Dutra (PSD-RS), evidenciam estes dois aspectos: a continuidade e a ruptura verificados no período. Políticos descrevem de forma cândida, inocente, como "faziam eleitores e as eleições", ao tempo que reagem aos custos crescentes envolvidos neste processo ${ }^{26}$. O principal objetivo do projeto era obter financiamento estatal, via criação de um Fundo Partidário a ser incorporado ao Orçamento Geral da União, por meio do qual os partidos seriam ressarcidos pelas suas despesas com alistamento, transporte e impressão de cédulas ${ }^{27}$.

Saudando o projeto, o deputado Fernando Ferrari (PTB-RS) afirma:

O alistamento pelas leis vigentes, pelo sistema atual, face à lei eleitoral, é, não há dúvida alguma, um ônus do Estado. Todavia, os partidos políticos, todos, aqui e acolá, têm-se adiantado a esse favor do Estado, fa- 
zendo eles mesmos o alistamento. Os partidos políticos têm substituído o Estado nessa função, através, inclusive, do proselitismo da busca do votante, da vinda dele ao escritório eleitoral, do preenchimento do formulário diante do Juiz Eleitoral, e assim por diante. São raros os eleitores neste país que se inscrevem diretamente no Tribunal Eleitoral. Creio que não fujo à realidade se afirmasse que 95 ou 96\% do eleitorado brasileiro é inscrito através dos órgãos partidários, com a cooperação destes que, como procuradores legais, levam o requerimento a registro para o competente processamento e despacho ( $D C N$, junho de 1953:5504).

Obviamente, é impossível saber com precisão a proporção do eleitorado inscrito pelos partidos. A estimativa feita por Ferrari pode conter exagero; contudo, revela que se tratava de prática corrente, disseminada e, mais importante, aceita. O alistamento individual e voluntário era a exceção. A norma era o alistamento feito pelo partido, cujos agentes se encarregavam de todos os trâmites. Como observa Ferrari, cabia ao chefe político local "levar o requerimento a registro para o competente processamento e despacho".

Os custos com alistamento e transporte eram vistos como um ônus, um serviço prestado ao Estado pelos partidos. Veja-se, a título de exemplo, o depoimento de Alberto Deodato (UDN-MG):

Eu fui presidente de um partido político, da UDN do Estado de Minas Gerais, o qual tinha despesas como nunca imaginei fossem feitas. Não são despesas para corrupção, não são despesas para comprar eleitores, mas despesas que, beneficiando o Partido, beneficiam toda a coletividade política. Por exemplo, fazer eleitor. Nenhum partido faz eleitor para o seu partido, faz eleitor em massa. A despesa é enorme. Em segundo lugar: o transporte no dia da eleição, o que é louvável, não só para o Partido como para as eleições, como também, para o próprio eleitor que se não tiver transporte pagará a multa; a alimentação do eleitor durante o dia da eleição, principalmente em Minas, onde as estradas são deficientes - tudo isso são despesas obrigatórias dos Partidos políticos. (DCN, 23/6/1953:5390)

O deputado João Cabanas (PTB-SP) ${ }^{28}$, por seu turno, oferece uma boa descrição das atividades envolvidas na distribuição de cédulas:

Nas eleições passadas, eu chegava muitas vezes num diretório com minhas cédulas e pedia que fossem distribuídas. A distribuição, porém, 
tinha de ser feita casando-se aquelas cédulas com outras para Presidente e Vice-Presidente, Senador, para Deputado Federal, Estadual, etc. Ora, esse serviço de casar 2.000, 3.000, 10.000 cédulas, quem o faz não é o cabo eleitoral, mas uma equipe de pessoas, 10 moças ou 10 crianças, que trabalham durante dias. Essas pessoas precisam de alimentos, de transporte e outras pequenas coisas. De modo que as exigências feitas pelos cabos eleitorais é coisa humana, natural, não pode sofrer crítica. (DCN, 1/7/1953:5051)

O "casamento" das cédulas pedia investimento prévio: as mesmas tinham que ser impressas e distribuídas. Todas estas despesas não seriam rentáveis se os candidatos não tivessem certeza de que o seu investimento redundaria em votos. Ou seja, era preciso garantir que as cédulas distribuídas fossem efetivamente depositadas nas urnas, de onde o complemento necessário de toda esta estratégia era o isolamento e a vigilância sobre o eleitor feito, omitida, por motivos óbvios, dos discursos parlamentares ${ }^{29}$. Orlando Carvalho (1946:152), discorrendo sobre as práticas eleitorais da eleição de 1945, oferece uma descrição desta parte essencial do processo:

O princípio a que obedece toda a técnica é o de preservar o roceiro de qualquer contato com os cabos eleitorais adversários, porque-é a triste verdade - ele geralmente vota com a última cédula que lhe é posta na mão. Para obter este isolamento, sem transformá-lo em prisão, os chefes da cidade e dos distritos, organizam os tradicionais "quartéis", [...] um prédio amplo [...] no qual os eleitores possam abrigar-se durante a noite, encontrando aí alimentação e diversão. [...] Do quartel, os eleitores da roça saem para votar, em grupos pequenos, guardados à vista por gente de confiança, disposta e armada, que impedirá a comunicação com elementos suspeitos ${ }^{30}$.

Fazer eleitores para fazer eleições era uma prática disseminada a que recorriam políticos de todos os matizes. Afonso Arinos de Melo Franco, por exemplo, ao rememorar a campanha de 1954, observa:

Ali pude ver o trabalho tremendo que é o preparo de um pleito eleitoral no sertão. O alistamento, a assistência aos eleitores a famílias, a prudente coragem de enfrentar a pressão das autoridades adversárias, sem falar das despesas com transporte, alimentação, vestimentas e abrigo nos 'quartéis'"' (1965:292).

Ao defender o Fundo Partidário, os políticos não questionam as práticas vigentes. Despesas com o alistamento, transporte e abrigo nos quartéis são tratadas como normais. Quando e se justificadas, são apresen- 
tadas como necessárias, um ônus, uma despesa que deveria caber ao Estado, mas assumida pelos políticos para evitar o absenteísmo. Este longo trecho do parecer da Comissão de Finanças ao projeto instituindo o Fundo Partidário é esclarecedor:

O regime democrático está fundado em eleições periódicas, quando o povo é chamado a escolher seus dirigentes e representantes. A União tem a seu cargo as despesas dessas funções. Consistem na manutenção da Justiça Eleitoral, aquisição de material e instalação de Mesas receptoras de votos. Estas são as despesas mínimas. Outras, porém, existem na realidade brasileira, que sempre estiveram a cargo dos políticos ou dos partidos. São aquelas que, em um país de elevado grau de civilização e de facilidade de transporte, podem ser feitas pelo próprio eleitor. É o alistamento eleitoral, é o transporte do eleitor para a sede da votação e a sua alimentação o dia da eleição que constituem os encargos dos partidos, em quase todo o interior do Brasil. São homens e mulheres do campo, de escalas e origens sociais diversas, que se deslocam para as cidades, vilas ou povoados mais próximos com o propósito de votar e que não dispondo de animais ou outros meios de transporte e nem de recursos com que custeiem alimentação fora de casa, sempre receberam uma e outra coisa dos interessados no pleito. Secular o costume, não há força que o revogue. (DCN, 11/4/1953:2504)

O problema a ser sanado, portanto, não era os costumes seculares, pois estes não seriam revogados mesmo com o emprego da força. O projeto solucionava um problema de outra ordem, mais exequível e mais pragmático, passível de ser moldado pela força da lei. O que se pretendia era atacar os custos envolvidos nestas práticas, que a despeito de seculares, passavam por transformações. O diagnóstico do parecer é claro: "Atingiu-se a um número de eleitores votantes que ultrapassa de muito as possibilidades do abnegado chefe municipal. Passaram os candidatos a cooperar nas despesas" (idem).

As despesas dos candidatos e dos partidos aumentam à medida que se veem impelidos a "fazer" um número crescente de eleitores, recorrendo para tanto a recursos de terceiros, perdendo, assim, a sua independência. A importância do chefe político local também cresce ao mesmo tempo que passa a ser disputado por candidatos. Como se lê no mesmo parecer:

Não poucas vezes o candidato afortunado domina as preferências dos chefes municipais ou cabos eleitorais ligados a outro de pouco recurso 
financeiro [...]. Passou a época em que os partidos podiam escolher homens de real valor moral e intelectual, com que pudessem compor bem a sua representação. Estaria isto certo, se eleitos fossem os que tivessem real prestígio eleitoral. Porque este se adquire à custa de serviços prestados à coletividade. Mas, também se estes não podem financiar as despesas mínimas de suas eleições, correm o risco da derrota. (DCN, 11/4/1953:2504)

Partidos e candidatos teriam sido lançados em um verdadeiro redemoinho: a competição por votos leva à competição pelos recursos usados para obter os votos. Este processo traz consigo a erosão das relações tradicionais entre políticos e chefes políticos locais. A competição pelos votos controlados pelos chefes políticos locais mina o modelo hierárquico descrito no Plano $B$. Cortejados por diferentes políticos carentes e necessitados de uma quantidade cada vez maior de votos para se eleger, o poder de barganha do chefe político local, do coronel descrito por Nunes Leal, cresce. Este não se vê mais impelido a apoiar automaticamente a política dominante no Estado.

A proposta visando a criação do Fundo Partidário pode ser vista como uma tentativa de reequilibrar as peças e as engrenagens sobre as quais se assentavam as relações políticas tradicionais. Políticos apresentam-se como as vítimas de um mundo em que o dinheiro passara a ser o principal trunfo. Ao saudar o projeto instituindo o Fundo Partidário, Fernando Ferrari (PTB-RS) afirma que o mesmo

traz no bojo principal da sua ideia o desejo de afastar dos partidos políticos a influência do poder econômico, o desejo de tornar os partidos não milionários, não poderosos economicamente, mas o suficientemente fortes para se contraporem as arremetidas exteriores deste ou daquele aventureiro que às vésperas dos pleitos eleitorais avassala consciências, compra votos... (DCN, junho de 1953:5504).

Joel Presídio (PTB-BA) apoia medidas legislativas que tragam consigo

modificações moralizadoras e de caráter urgente, modificações que impeçam a influência do poder econômico nos futuros pleitos, modificações que cheguem talvez, pela energia, a violência contra aqueles que se servirem do dinheiro para corromper consciências, para comprar cabos eleitorais, contra aqueles, enfim, que, por terem nascido em berço de ouro ou enriquecido de um momento para outro, em negócios escusos, se julgam com o direito de, às vésperas de um pleito, candidatarem-se a 
cargos eletivos [...] comprando cadeiras e mandatos como se compram ingressos nos circos de cavalinho. (DCN, 26/8/1953:809, ênfases minhas)

Políticos denunciam a importância cada vez maior que o dinheiro estaria assumindo nas eleições. A necessidade de buscar recursos para financiar as atividades tradicionais (alistar, transportar e distribuir cédulas) é vista como uma fonte de corrupção. Idealiza-se um mundo em que os recursos individuais dos políticos seriam suficientes para fazer eleitores e eleições. A conclusão do parecer da Comissão de Finanças não poderia ser mais explícita quanto a este ponto:

Dotados os partidos de recursos financeiros que bastem às despesas mínimas de uma eleição, de certo poderão não ter forças para impedir gastos perdulários de um candidato rico, mas terão para recusar-lhe a legenda, porque já não dependerão de sua fortuna. Para os partidos e homens de real prestígio na opinião pública é preciso apenas que possam alistar e fazer comparecer o eleitorado. (DCN, 11/4/1953:2504)

A essência das práticas eleitorais vigentes não é denunciada ou associada à corrupção; alistar e fazer comparecer o eleitorado são práticas normais e aceitas. Políticos são corrompidos, perdem sua independência quando precisam recorrer a recursos de terceiros. Ou seja, o objetivo central do Fundo era tão somente o de prover os partidos com recursos para que estes pudessem continuar a fazer o que sempre haviam feito, isto é, eleitores e eleições.

\section{CONCLUSÕES}

Do ponto de vista das práticas eleitorais, pouco mudou entre a Primeira e a Terceira Repúblicas. O voto secreto forçou adaptações, mas não alterou o essencial: o controle sobre o comportamento dos eleitores. Transportar eleitores implicava mais do que simplesmente providenciar o deslocamento às seções eleitorais. Eleitores eram "aquartelados" nas sedes dos municípios em que votavam. Era preciso ter garantias que compareceriam e, sobretudo, que teriam em mãos as cédulas corretas. Aquartelar, portanto, significava isolar o eleitor, impedir que este entrasse em contato com os cabos eleitorais dos demais candidatos.

O voto secreto não impede que políticos controlem o voto dos eleitores que alistam e levam a votar. Ainda assim, a despeito desta continuidade, há uma diferença significativa em relação à Primeira República. 
Eleições passam a ser competitivas. Para ser eleito, políticos têm que fazer um grande número de eleitores. O crescimento do eleitorado é a evidência indireta da incerteza quanto aos resultados das eleições.

A Primeira República caracteriza-se pela baixa participação. Defini-la como oligárquica é simplesmente nomear o que precisa ser explicado. Entre 1894 e 1926, nas eleições presidenciais, a porcentagem de votantes sobre a população variou entre 1,50\% e 3,34\%. Na eleição de 1930, os números apresentam uma forte inflexão, alcançando $5 \%$ da população, ficando bem acima da norma anterior ${ }^{31}$.

A mobilização que antecede a eleição de 1930 aponta para a relação positiva entre competição e mobilização eleitoral. O raciocínio é simples e imediato; para vencer eleições é preciso fazer e trazer para votar um maior número de eleitores. Tanto Júlio Prestes quanto Getúlio Vargas lançaram mão desta estratégia. O resultado foi o crescimento da participação.

Prestes e Vargas, contudo, só puderam fazer eleitores nos estados em que eram apoiados pelos respectivos governadores. Na eleição de 1945, PSD e UDN não se deparam com a mesma restrição. Análise dos resultados desta eleição revela que ambas as candidaturas puderam "fazer eleitores" em praticamente todos os municípios do país, uma vez que são raras as localidades inteiramente dominadas por um dos candidatos. Em apenas 10 dos 357 municípios para os quais há dados, um dos candidatos recebeu mais do que $90 \%$ dos votos. Somente em 40 municípios um deles obteve votação superior a $80 \%$. Na maioria dos municípios, como se vê, ambos os candidatos foram capazes de marcar presença ${ }^{32}$.

Os políticos da Terceira República percebem e reagem à nova realidade em que se movimentam. Os autores do parecer da Comissão de Finanças que apoia a criação do Fundo Partidário notam de forma clara a diferença entre as duas realidades quando afirmam que durante a Primeira República "os governos tinham certa a vitória e as oposições a derrota" e por isto "funcionava plenamente a lei do menor esforço" isto é, o "alistamento mínimo", e eram, "consequentemente, muito pequenas as despesas com a realização de eleições" (DCN, 11/4/1953: 2504). Já no período iniciado em 1945 , a realidade seria outra porque as oposições, confiando no "legítimo resultado dos pleitos, passaram a tomar o mais vivo interesse no alistamento eleitoral, obrigando o situacionismo a agir da mesma forma" (ibidem). 
Não se poderia pedir caracterização melhor. A contraposição é clara. O essencial, o elemento distintivo, é a incerteza quanto aos resultados eleitorais. A divisão interna das elites políticas faz com que estas passem a competir pelos votos controlados por diferentes chefes locais. E isto significa que competem também pelos recursos empregados por estes para fazer eleitores.

Se tanto o governo quanto a oposição sabem com certeza que o primeiro vencerá as eleições, ambas as partes não têm incentivos para mobilizar eleitores. O alistamento mínimo é suficiente desde que a situação (o governo) tenha como assegurar esta vantagem. Uma possível ameaça da oposição de mobilizar eleitores e levá-los às urnas pode ser neutralizada. O controle sobre o alistamento é uma condição necessária para que o governo tenha certeza da vitória.

Rachel de Queiroz, que serviu de mesária na eleição de 1945, oferece um contraste tão vivo como eloquente das eleições dos dois períodos:

Não sei bem se o sentimento será de saudade; mas a verdade é que eleição mudou muito. Recordo da eleição do tempo de dantes - tiro, comedorias, botinas de graça para os eleitores, cachaça a rodo, era um carnaval. Votava vivo e votava morto, votava doido do hospício, só não votavam nossos inimigos políticos (apud Leal, 1993:242).

O crucial é se os inimigos políticos poderão ou não votar. As demais características dos eleitores, se doidos ou mesmo se mortos, são menos relevantes. A lista poderia prosseguir: educação, renda, grau de consciência, independência etc. Estas distinções não importam. Não são elas que discriminam a característica efetivamente relevante. O que importa é a afinidade política do eleitor, em quem ele votará. Dito de outra forma, a qualificação do eleitor que efetivamente importa não é dada por sua capacidade, como quer que esta seja medida, mas, sim, por sua inclinação partidária, por quem o fez eleitor e o leva a votar, se os amigos ou os inimigos, se o governo ou a oposição. Parafraseando Rachel de Queiroz, há competição quando votam os nossos amigos e os nossos inimigos.

(Recebido para publicação em maio de 2014) (Aprovado para publicação em setembro de 2014) 


\section{NOTAS}

1. Cox (2005) afirma que a competição eleitoral passa por três atividades: persuasão (formação da vontade dos eleitores), mobilização (fazer com que seus partidários de fato votem) e coordenação (evitar votos em candidatos sem chances de vitória). Nichter (2008) e Ganz-Morse, Mazzuca e Nichter (2009) desenvolvem e aplicam a tipologia proposta por Cox.

2. Ver Porto (2002:120) e Graham (1990:182 e ss.) para a ênfase nas exigências formais introduzidas pela Lei Saraiva e como estas operavam como barreiras ao alistamento. Nicolau (2012:46) e Paiva (1985:106) mostram como os controles formais foram mantidos durante a Primeira República.

3. O documento está disponível para consulta em http://docvirt.com/docreader FGV/docreader.aspx?bib=CorrespGV2\&PagFis=15959 (Arquivo Getulio Vargas, 43.000.00/3, CPDoc/FGV).

4. Pesou para esta escolha o fato de o governo saber que Dutra havia sido sondado pelas forças oposicionistas. Segundo alguns relatos (Vale, 1978:40; Caó, 1949:222) líderes das forças de oposição teriam oferecido a Dutra a candidatura à Presidência. Ou seja, Dutra oferecer a candidatura oficial do governo foi a forma de manter o Exército alinhado com o governo.

5. Gomes afirma: "Em relação ao PSD o problema é mais simples. Os interventores estaduais, representando o que de mais significativo existia em termos de novas elites políticas, reuniram-se para implementar o seu partido. Com isso, estavam vedando definitivamente a ideia de um grande partido de massas, e estabelecendo a criação de um partido nacional da cúpula governamental estado-novista gerido em termos de colegiado e com bases políticas regionais" (2005:282).

6. A votação total do PTB para a Câmara foi 603.500 votos, dos quais pelo menos 318.315 foram dados a Vargas.

7. Benevides (1981:29) distingue cinco grupos na composição original da UDN, a saber, os antigos aliados de Getúlio em 1930, marginalizados antes ou depois do Estado Novo; os que participaram do Estado Novo e se afastaram antes de 1945; oligarcas destronados em 1930; grupos liberais com forte identificação regional e, por fim, as esquerdas. Em geral, assume-se que os dois últimos grupos foram os mais importantes para a criação do partido enquanto o papel dos dois primeiros é minimizado.

8. Benevides (1981:28) afirma que a despeito de suas negativas, Oswaldo Aranha teria participado da criação da UDN, estando presente inclusive na reunião de fundação do partido, apoiando a candidatura Eduardo Gomes.

9. A passagem completa é a seguinte: "Os resultados bastante apreciáveis, sob o ponto de vista formal, dos pleitos de 2 de dezembro de 1945 e de 19 de janeiro de 1947 foram devidos, contudo, em grande parte, a circunstâncias excepcionais em nossa história política. Em primeiro lugar, no período de 'governo dos juízes', o Chefe de Estado e os interventores, via de regra, recomendaram aos seus subordinados isenção de ânimo na direção da eleição federal." Uma nota complementa a observação: "É bem expressiva a esse propósito a substituição dos prefeitos determinada pelo Governo Linhares".

10. Vale acrescentar: a UDN aceitou disputar as eleições sem alterar a Lei Agamenon. Muito provavelmente o fez porque acreditava que venceria. 
11. A frase citada acima é complementada pela citação de Virgílio de Melo Franco (1946:121), cujo teor parece ter influenciado decisivamente as interpretações sobre o período: "O alistamento $e x$-officio [...] foi calculadamente estendido às massas menos esclarecidas, enquadradas pelas organizações fascistas a que tinham sido reduzidos, pelo Estado Novo, os sindicatos, possibilitando assim a inclusão dos analfabetos e dos estrangeiros."

12. Nas eleições para a Constituinte de 1933 o eleitorado foi de 1,4 milhão de eleitores, registrando, portanto, uma queda significativa em relação à última eleição presidencial. Registra-se, contudo, forte crescimento nas eleições estaduais realizadas em 1934, quando os registros indicam um total de 2,6 milhões de eleitores (IBGE, 1960).

13. Na realidade, a Lei Agamenon não regulava explicitamente esta possibilidade. O Decreto-Lei 7.926 de 3/9/1945 autoriza explicitamente o alistamento por terceiros, incluindo os partidos políticos entre os agentes autorizados a promovê-lo.

14. Como veremos, o Código Eleitoral de 1950 manteve esta ambiguidade fundamental.

15. Significativamente, até hoje, as estatísticas do TSE distinguem eleitores que leem e escrevem dos que têm ensino fundamental incompleto. Ou seja, para o TSE a educação formal não é condição para a alfabetização.

16. Vale observar que o TSE também publica estatísticas que discriminam o gênero dos eleitores. Nem sempre é notado que o voto era voluntário para as mulheres que não exercessem atividades remuneradas. Para os estados para os quais há dados, para cada três homens alistados, havia apenas uma mulher na mesma condição. Sendo assim, é de se supor que a grande maioria dos homens em idade de votar era alistada, independente da sua educação. Mas esta é apenas uma suposição.

17. Não é demais notar que os dados apresentados por Victor Nunes Leal para caracterizar a estrutura agrária do país são do censo de 1940.

18. Referindo-se ao alistamento ex-officio, Kinzo (1980:81) afirma: "Além do alistando poder ser qualificado através de uma simples lista preparada por empregadores e agências governamentais, o Tribunal Eleitoral remetia aos organizadores das listas os títulos eleitorais que por esses seriam preenchidos, tendo o alistando apenas o trabalho de assiná-lo no próprio emprego, o que levava ao alistamento de analfabetos, uma vez que nenhuma prova existia que comprovasse ser ele alfabetizado". O processo de alistamento não era diverso no caso de este ser feito por requerimento.

19. João C. da Rocha Cabral (2004:39), por exemplo, ao comentar as inovações do Código Eleitoral de 1932, afirma que um de seus objetivos centrais era o de combater o absenteísmo e que para tanto era preciso facilitar "mais e mais os processos de alistamento, que hoje, prima facie, parecem complicados". Augusto O. Gomes de Castro (1936:70), de sua parte, afirma que "todas as medidas tendentes a reduzir ao mínimo o incômodo que a inscrição eleitoral causa ao alistando, facilitando o alistamento, devem merecer a simpatia do legislador". Ambos listam o alistamento ex-officio como medida simplificadora deste processo.

20. Os dados apresentados nas Tabelas 1 e 2 são demasiadamente agregados para tratamento estatístico mais sério. Ainda assim, vale observar que há uma correlação negativa entre as porcentagens das duas tabelas. Isto é, onde foi maior o alistamento ex-officio, menor a proporção de eleitores potenciais alistados (a correlação não deixa de ser alta: 0,37 ). A proporção de votos recebidos por Dutra com o alistamento ex-officio é praticamente zero. Note-se que Dutra tem uma de suas piores votações na 


\section{Fernando Limongi}

cidade do Rio de Janeiro, justamente onde mais eleitores foram alistados por este método. A correlação entre votos em Dutra e eleitorado potencial alistado é negativa, mas não muito alta $(0,15)$.

21. Os títulos expedidos até a entrada da vigência da nova lei permanecem válidos.

22. Testes comprobatórios da qualificação eram previstos apenas em casos de denúncia de que o eleitor não era alfabetizado. O modo de fazê-lo era deixado à discrição do juiz eleitoral.

23. Para um exame mais aprofundado da ampliação da participação neste período, consultar Limongi, Cheibub e Figueiredo (2015).

24. No caso das eleições presidenciais, a UDN consegue aprovar a adoção da cédula oficial. A este respeito, consultar Gingerich (2012).

25. O recadastramento começa imediatamente depois da eleição presidencial de 1955, mas só é efetivado na eleição de 1958.

26. Em 1949, Domingos Velasco, da ala Esquerda Democrática da UDN (ED/UDN-GO), apresenta emendas ao novo Código Eleitoral visando obter subsídio estatal para as despesas dos partidos com alistamento, transporte e impressão de cédulas. As justificativas que apresenta antecipam o projeto de Tarso Dutra. Ver, especialmente, DCN (24/5/1949:4213 e 6/4/1949:2540).

27. O Fundo, a ser incluído no Orçamento Geral da União, seria composto, fundamentalmente, por duas fontes, a saber, os provenientes da arrecadação de um "selo cívico" a ser instituído e de uma parcela do imposto sobre a renda e proventos de qualquer natureza. Os recursos seriam distribuídos aos partidos de acordo com a fórmula que levava em conta o seu desempenho nas eleições anteriores.

28. Cabanas, em realidade, critica aspectos específicos do projeto de Dutra, propondo projeto alternativo, o PL 3.220/1953, com o mesmo fim.

29. A vigilância sobre eleitores, contudo, não é inteiramente ignorada. Ao longo da aprovação do Código Eleitoral de 1950, Domingos Velasco (ED/UDN-GO) afirma que “Quem acompanhou as últimas eleições sabe que em muitos municípios foram os partidos organizados a organizar uma verdadeira polícia que impedisse as equipes de cabos eleitorais menos escrupulosos de subtraírem as cédulas já distribuídas aos correligionários" (Anais DCN, 24/5/1949:4213).

30. As diversas estratégias usadas para ludibriar os eleitores e os cabos eleitorais são descritas por Carvalho (1958:44). Para práticas similares nos Estados Unidos, consultar Bensel (2004). Ver também os verbetes "curral" e "quartel" em Porto (1995).

31. As duas outras eleições presidenciais mais competitivas, a de 1910 e 1922, também registram participação acima da média.

32. Estes dados são resultado de levantamento original nos arquivos do TSE levado a cabo no interior do consórcio Redescobrindo o Brasil. A compilação destes foi feita de maneira diligente e competente por Saulo Said, doutorando do Instituto de Estudos Sociais e Políticos (IESP) da Universidade do Estado do Rio de Janeiro (UERJ), a quem agradeço por compartilhar suas análises iniciais para a elaboração deste artigo. 


\section{REFERÊNCIAS BIBLIOGRÁFICAS}

AMORIM NETO, Octávio. (1995), Cabinet Formation and Party Politics in Brazil. Trabalho apresentado no XIX Congresso Internacional da Latin American Studies Association, Washington, DC, 28-30 de setembro.

BENEVIDES, Maria Victoria de Mesquita. (1981), UDN e o Udenismo. Ambiguidades do Liberalismo Brasileiro (1945-1964). São Paulo, Paz e Terra.

BENSEL, Richard Franklin. (2004), The American Ballot Box in the Mid-Nineteenth Century. New York, Cambridge University Press.

CABRAL, João C. da Rocha. (2004) [1932], Código Eleitoral da República dos Estados Unidos do Brasil de 1932. (Edição Especial). Brasília, Senado Federal.

CARVAlHO, Orlando M. (1946), A Política do Município. Rio de Janeiro, Livraria Agir Editora.

(1958), Ensaios de Sociologia Eleitoral. Belo Horizonte, Universitária de Minas Gerais.

CAÓ, José. (1949), Dutra: O Presidente e a Restauração Democrática. São Paulo, Instituto Progresso Editorial.

CASTRO, Augusto O. Gomes. (1936), O Novo Código Eleitoral. Rio de Janeiro, A. Coelho Branco Filho Editor.

COX, Gary. (2005), "Electoral Institutions and Political Competition. Coordination, Persuasion, and Coordination", in C. Menard e M. M. Shirley (orgs.), Handbook of New Institutional Economics. Dordrecht, Springer, pp. 69-89.

DELGADO, Lucilia de Almeida Neves. (1989), PTB: Do Getulismo ao Reformismo (1945-1964). São Paulo, Marco Zero.

DULLES, John W. F. (1967), Getúlio Vargas, Biografia Política. (2a ed.). Rio de Janeiro, Renes.

FIGUEIREDO, Argelina Cheibub. (2007), "Coalition Government in the Brazilian Democracy". Brazilian Political Science Review, vol. 1, pp. 182-216.

FRANCO, Afonso Arinos de Melo. (1965), A Escalada. Memórias. Rio de Janeiro, José Olympio Editora.

FRANCO, Virgílio de Melo. (1946), A Campanha da UDN (1944-1945). Rio de Janeiro, Livraria Editora Zelio Valverde.

GANZ-MORSE, Jordan; MAZZUCA, Sebastián e NICHTER, Simeon. (2009), "Who Gets Bought? Vote Buying, Turnout Buying and others Strategies". Working Paper 2009-0006. Wetherhead Center for International Affairs. Boston, Harvard University.

GINGERICH, Daniel. (2012), Can Institutions Cure Clientelism? Assessing the Impact of the Australian Ballot in Brazil. Trabalho apresentado na 70a Annual Midwest Political Science Association Conference, Chicago, 11-15 de abril.

GOMES, Ângela Castro. (2005), A Invenção do Trabalhismo. (3a ed.). Rio de Janeiro, FGV Editora. 


\section{Fernando Limongi}

GRAHAM, Richard. (1990), Patronage and Politics in Nineteenth-Century Brazil. Stanford, Stanford University Press.

HIPPOLITO, Lucia. (1985), De Raposas e Reformistas. O PSD e a Experiência Democrática Brasileira (1945-1964). Rio de Janeiro, Paz e Terra.

IBGE (Instituto Brasileiro de Geografia e Estatística). (1960), Anuário Estatístico do Brasil: 1960. Ano XXI. Rio de Janeiro, Conselho Nacional de Estatística.

KANG, Thomas Hyeono. (2010), Instituições, Voz Política e Atraso Educacional no Brasil. Dissertação de mestrado. Faculdade de Economia e Administração, Universidade de São Paulo.

KINZO, Maria D’Alva Gil. (1980), Representação Política e Sistema Eleitoral no Brasil. São Paulo, Edições Símbolo.

LEAL, Victor Nunes. (1993), Coronelismo, Enxada e Voto. São Paulo, Alfa-Ômega.

LIMONGI, Fernando. (2012), “Eleições e Democracia no Brasil. Victor Nunes Leal e a Transição de 1945". DADOS - Revista de Ciências Sociais, vol. 55, no 1, pp. 131-163.

; CHEIBUB, José Antonio e FIGUEIREDO, Argelina. (2015), “Participação Política no Brasil", in M. Arretche (org.), Trajetórias da Desigualdade: Como o Brasil Mudou nos Últimos Cinquenta Anos. São Paulo, Editora UNESP.

NICHTER, Simeon. (2008), "Vote Buying or Turnout Buying? Machine Politics and the Secret Ballot". American Political Science Review, vol. 102, no 1, pp. 19-31.

NICOLAU, Jairo. (2012), Eleições no Brasil. Do Império aos Dias Atuais. Rio de Janeiro, Zahar Editores.

PAIVA, Maria Arair Pinto. (1985), Direito Político do Sufrágio no Brasil (1822-1982). Brasília, Thesaurus Editora.

PORTO, Walter Costa. (1995), Dicionário do Voto. São Paulo, Editora Giordano. (2002), O Voto no Brasil. (2a ed.). Rio de Janeiro, Topbooks.

PRZEWORSKI, Adam. (1991). Democracy and the Market. Political and Economic Reforms in Eastern Europe and Latin America. New York, Cambridge University Press.

SOUZA, Francisco Belisário Soares de. (1979), O Sistema Eleitoral do Império. Brasília, Senado Federal.

SOUZA, Maria do Carmo Campello de. (1990), Estado e Partidos Políticos no Brasil (1930-1964). São Paulo, Alfa-Ômega.

VALE, Osvaldo Trigueiro do. (1978), O General Dutra e a Redemocratização de 1945. Rio de Janeiro, Civilização Brasileira. 


\title{
RESUMO
}

Fazendo Eleitores e Eleições: Mobilização Política e Democracia no Brasil pós-Estado Novo

O artigo avalia a emergência de eleições competitivas no Brasil após a queda do Estado Novo. O objetivo central do texto é demonstrar que a independência dos eleitores - a liberdade do voto - não é uma condição necessária para a emergência de eleições competitivas. Sugere-se, portanto, que a adoção do voto secreto não levou a uma mudança significativa das práticas eleitorais, pois elites políticas mantiveram o controle sobre o comportamento dos eleitores. Para que eleições se tornem competitivas é essencial que diferentes grupos políticos possam mobilizar eleitores para fazer e ganhar as eleições. Para tanto, é preciso que o governo perca o controle do governo sobre o alistamento eleitoral.

Palavras-chave: democratização; eleições; competição; mobilização; voto

\author{
ABSTRACT \\ Making Voters and Elections: Political Mobilization and Democracy in \\ Brazil in the post-New State Period
}

This article assesses the emergence of competitive elections in Brazil after the fall of the "New State". The main goal of the text is to demonstrate that the independence of electors - the freedom to vote - is not a necessary condition for the emergence of competitive elections. To this end, it is suggested that the adoption of the secret vote did not entail significant changes in electoral practices, as the political elites remained in control of the behavior of voters. In order for elections to become competitive it is essential that different political groups are capable of mobilizing electors to carry out and win elections. To this end, the government ought to lose control of electoral enrollment.

Keywords: democratization; elections; competition; mobilization; vote 


\section{RÉSUMÉ}

La Fabrique des Électeurs et des Élections: Mobilisation Politique et Démocratie dans le Brésil post-État Nouveau

Cet article analyse l'émergence d'élections compétitives au Brésil après la chute de "l'État Nouveau". Le principal objectif de ce texte est de démontrer que l'indépendance des électeurs - la liberté du vote - n'est pas une condition nécessaire à l'émergence d'élections compétitives. Il est ainsi suggéré que l'adoption du vote secret n'a pas impliqué de changement significatif dans les pratiques électorales, étant donné que les élites politiques ont pu garder le contrôle du comportement des électeurs. Pour que les élections soient véritablement compétitives, il est essentiel que différents groupes politiques puissent mobiliser les électeurs pour participer aux élections et être en mesure de les gagner. À cette fin, le gouvernement ne peut plus être le seul maître de l'inscription des citoyens sur les listes électorales.

Mots-clés: démocratisation; élections; compétition; mobilisation; vote

\section{RESUMEN}

Haciendo Electores y Elecciones: Movilización Política y Democracia en el Brasil post-Estado Nuevo

El artículo examina la emergencia de elecciones competitivas en Brasil tras la caída del Estado Nuevo. El objetivo central del texto es demonstrar que la independencia de los electores - la libertad de voto - no es una condición necesaria para la emergencia de elecciones competitivas. De esta manera, el texto sugiere que la adopción del voto secreto no llevó a un cambio significativo de las prácticas electorales, dado que las elites políticas mantuvieron el control sobre el comportamiento de los electores. Para que elecciones sean competitivas es esencial que diferentes grupos políticos puedan movilizar electores para hacer y ganar elecciones. Para ello, es necesario que el gobierno pierda el control del gobierno sobre el alistamiento electoral.

Palabras clave: democratización; elecciones; competición; movilización; voto 